Check for updates

Cite this: RSC Adv., 2017, 7, 51744

Received 20th September 2017 Accepted 2nd November 2017

DOI: 10.1039/c7ra10439a

rsc.li/rsc-advances

\section{Self-powered UV-visible photodetector with fast response and high photosensitivity employing an Fe: $\mathrm{TiO}_{2} / \mathrm{n}$-Si heterojunction $\uparrow$}

\author{
Lin Sun, ${ }^{a}$ Chunrui Wang, (D) *a Tao Ji, ${ }^{\text {ab }}$ Jiale Wang, ${ }^{a}$ Gyu-Chul $\mathrm{Yi}^{\mathrm{C}}$ \\ and Xiaoshuang Chen ${ }^{\text {ad }}$
}

\begin{abstract}
An ultrasensitive, fast response and self-powered photodetector would be preferable in practical applications. In this paper, we report fast response, high photosensitivity and self-powered Fe doped $\mathrm{TiO}_{2}\left(\mathrm{Fe}_{\mathrm{TiO}}\right) / \mathrm{n}$-Si UV-visible detectors via a facile solution process. As-fabricated devices exhibited excellent photoresponse properties, including high responsivity of $46 \mathrm{~mA} \mathrm{~W}^{-1}(350 \mathrm{~nm})$ and $60 \mathrm{~mA} \mathrm{~W}^{-1}$ $\left(600 \mathrm{~nm}\right.$ ) with $0.5 \mathrm{~mW} \mathrm{~cm}^{-2}$ light irradiation under zero bias, as well as an ultrasensitive (on/off ratio up to $10^{3}$ ), fast (rise/decay time of $<10 / 15 \mathrm{~ms}$ ), and broad-band (UV-visible) photodetection with no or low external energy supply. Furthermore, the quantum efficiency of the heterojunction rose up beyond $100 \%$ with a broad wavelength range at a small reverse bias of $-0.5 \mathrm{~V}$. The self-power originated from the existence of a built-in electric field between $\mathrm{Fe}: \mathrm{TiO}_{2}$ and $\mathrm{Si}$ that helps facilitate the separation of photogenerated electron-hole pairs and regulate the electron transport. Capacitance-voltage $(C-V)$ measurements of $\mathrm{Fe}: \mathrm{TiO}_{2} / \mathrm{n}$-Si devices also confirmed the existence of the built-in electric field. Such $\mathrm{Fe}: \mathrm{TiO}_{2} / \mathrm{n}$-Si heterojunction photodetectors might be potentially useful for relative applications with weak-signal fast detection in the UV-visible band.
\end{abstract}

\section{Introduction}

In recent years, functional nanosystems must not only be sensitive, controllable and multifunctional, but must also have a low power consumption. Self-driven or self-sufficient nanodevices and nanosystems have recently attracted a lot of attention due to their various superior performance advantages., ${ }^{\mathbf{1 2}}$ Among them, many reports about self-powered photodetectors (PDs) have proved that they can operate independently and sustainably. ${ }^{3-11}$ This not only enhances the adaptability of the device, but also greatly reduces the size and cost of the system. In practical applications including imaging techniques, lightwave communication, and environmental sensing, ultrasensitive and fast response self-powered PDs would be more urgently needed. However, small photocurrent response, slow temporal

${ }^{a}$ Department of Applied Physics, State Key Laboratory for Modification of Chemical Fibers and Polymer Materials, Donghua University, 2999 Renmin Rd North, Songjiang District, Shanghai, P. R. China.E-mail: crwang@dhu.edu.cn

${ }^{b}$ School of Fundamental Studies, Shanghai University of Engineering Science, 333 Long Teng Road, Songjiang District, Shanghai, P. R. China

${ }^{c}$ Department of Physics and Astronomy, Seoul National University, Seoul 151-747, Korea.E-mail: gcyi@snu.ac.kr

${ }^{d}$ National Laboratory for Infrared Physics, Shanghai Institute of Technical Physics, Chinese Academy of Science, Shanghai 200083, P. R. China. E-mail: xschen@mail. istp.ac.cn

† Electronic supplementary information (ESI) available. See DOI: 10.1039/c7ra10439a recovery, narrow range of detectable light wavelengths and high detectable light intensities are the limitations for self-powered PDs. In addition, photoelectrochemical (PEC) self-powered systems have the problems of electrolyte toxicity and volatilization, and most of the PEC PDs only respond to the ultraviolet band region. ${ }^{5,6}$ Some routes introducing plasmonic materials, ${ }^{7}$ ferroelectric materials, ${ }^{8}$ monolayer graphene film as transparent electrode, ${ }^{9}$ high-quality single crystals obtained via molecular beam epitaxy ${ }^{\mathbf{1 0}}$ have been developed to further improve device performance. However, additional complexity of the processing and the high cost limit their practical applications. Therefore, high performance and reliable self-powered PDs fabricated by a facile and low cost way is necessary.

Benefiting from the mature silicon (Si)-based process in the microelectronics industry, semiconductor/Si vertical heterojunction PDs, with a planar device structure, have attractive applications in the optoelectronic integrated circuits. ${ }^{\mathbf{1 2 - 1 7}}$ The construction of semiconductor nanostructure materials/Si heterojunction can not only compensate for the limited spectral bandwidth of Si due to the extensive absorption spectra of different semiconductor materials (especially for UV applications), but also promote the separation and transport of photoinduced carriers. Among them, wide-bandgap semiconductor materials $\mathrm{ZnO}$ and $\mathrm{TiO}_{2}$ has been widely investigated. In contrast, the chemical stability of $\mathrm{TiO}_{2}$ is more stable than $\mathrm{ZnO}$. And it has been proved that the optical sensitivity and activity of $\mathrm{TiO}_{2}$ can be improved by ion doping. Ion doping of $\mathrm{TiO}_{2}$ either 
introduce impurity energy level(s) or adding energy states to band edge, as a consequence, spectral response range can be broadened. ${ }^{18-23}$ In Fe-doped $\mathrm{TiO}_{2}\left(\mathrm{Fe}: \mathrm{TiO}_{2}\right), \mathrm{Fe}^{3+}$ ions tend to substitute for $\mathrm{Ti}^{4+}$ ions and take their lattice sites. $\mathrm{Fe}^{3+}$ cations can act as shallow traps to decrease of the recombination rate (see Fig. S4, ESI $\dagger$ ). ${ }^{17}$ Some good self-powered PDs based on $\mathrm{TiO}_{2}$ have been reported, such as $\mathrm{TiO}_{2}-\mathrm{SnO}_{2},{ }^{6} \mathrm{TiO}_{2}-\mathrm{PANI},{ }^{24} \mathrm{TiO}_{2}-$ $\mathrm{CH}_{3} \mathrm{NH}_{3} \mathrm{PbI}_{3}$ (ref. 25) and so on. But as far as we know, there are few reports on photodetection with doping of $\mathrm{TiO}_{2}$. Herein, we designed a novel self-powered UV-visible PD employing heterojunction between the Fe:TiO ${ }_{2}$ and Si. Such Fe:TiO $2 / n-S i$ heterojunction fabricated by a facile and low cost way, with high performance and reliable PDs, it can be used for broad-band (UV-visible) photodetection in a self-powered mode operation. The built-in electric field formed between the interfaces creates the driving force for the fast and efficient separation of the photogenerated carriers. A fast response speed of 10/15 ms were achieved in the fabricated PDs. Notably, under zero bias, the device exhibited high responsivity of $46 \mathrm{~mA} \mathrm{~W}^{-1}(350 \mathrm{~nm})$ and $60 \mathrm{~mA} \mathrm{~W}^{-1}(600 \mathrm{~nm})$ with a $0.5 \mathrm{~mW} \mathrm{~cm}^{-2}$ light irradiation. At a small reverse bias of $-0.5 \mathrm{~V}$, the quantum efficiency of the device rose up beyond $100 \%$ with a UV-visible wavelength range. The novel device design described in this paper may point out a promising new direction for manufacturing advanced selfpowered PDs.

\section{Experimental}

\section{Materials synthesis and characterization}

$3 \mathrm{~mL}$ of tetrabutyl titanate $\left(\mathrm{C}_{16} \mathrm{H}_{36} \mathrm{O}_{4} \mathrm{Ti}\right)$ solution was stirred with $10 \mathrm{~mL}$ of ethanol solution overnight, and $0.02 \mathrm{M}$ anhydrous ferric chloride $\left(\mathrm{FeCl}_{3}\right)$ ethanol solution was stirred overnight. Two sols were mixed with magnetic stirring until homogeneous. The above process avoided water involvement. Light yellow sol was spin-coated at n-Si (111) $(8-13 \Omega \mathrm{cm})$ wafer with $1000 \mathrm{rpm}$ for $10 \mathrm{~s}$. Subsequently annealed under an air atmosphere in muffle furnace at $400{ }^{\circ} \mathrm{C}$ for 1 hour and spontaneously cooled to room temperature. Namely, Fe:TiO $2 / n-S i$ heterojunction nanostructure samples were obtained.

Morphology of $\mathrm{Si} / \mathrm{TiO}_{2}$ heterojunction were determined by a field emission scanning electron microscope (FESEM, Hitachi, $\mathrm{S}-4800$ ). Powder X-ray diffraction (XRD) of the samples was conducted by a D/max-2550VB+/PC X-ray diffractometer (Rigaku, Japan) equipped with a rotating anode and a $\mathrm{Cu} \mathrm{K} \alpha$ radiation source $(\lambda=1.54056 \AA)$. Raman spectra were recorded at room temperature on an inVia-Reflex micro-Raman spectroscopy system from Renishaw with $532 \mathrm{~nm}$ radiation. Room temperature UV-vis absorption spectroscopy was conducted on a Shimadzu UV3600 UV-vis-NIR spectrophotometer. XPS data were obtained using an Escalab 250Xi (Thermo Scientific) spectrometer with an excitation source of $\mathrm{Al}-\mathrm{K} \alpha$ radiation. Photoluminescence (PL) measurements were carried out at room temperature using fluorescence spectroscopy (PTI QuantaMaster) with a xenon lamp as the excitation source $\left(\lambda_{\mathrm{ex}}=370\right.$ $\mathrm{nm})$.

\section{Photodetector fabrication and measurement}

The top electrode is Ag-planted digitated finger shape with total surface area of $25 \mathrm{~mm}^{2}$. The bottom of the Si wafer was coated with an $\mathrm{Ag}$ layer as a bottom electrode. To illustrate the reliability of the manufacturing process, sample A, B, C and D were prepared under the same conditions, and the following test data was based on sample A if there are no special instructions. The current-voltage $(I-V)$ curves and capacitance-voltage $(C-V)$ characteristic of the device were measured by using the Keithley-4200 semiconductor characterization system (SCS) on a probe station at room temperature. Monochromatic light with wavelength ranging from 350 to $600 \mathrm{~nm}$ was achieved from a $300 \mathrm{~W}$ Xenon lamp with monochromators.

\section{Results and discussion}

\section{Characterization}

SEM image showing the morphology and structure of asfabricated heterojunctions consisting of $\mathrm{TiO}_{2}$ and $\mathrm{Fe}: \mathrm{TiO}_{2}$ thin film/Si wafer via a solution process of spin coating (Fig. 1a and b). As can be seen from the cross-section of heterojunction, the nanoscale particles formed a dense film with a thickness of about $200 \mathrm{~nm}$. The pure and Fe-doped $\mathrm{TiO}_{2}$ were characterized by XRD. As shown in Fig. 1c, all XRD peaks are indexed to the $\mathrm{TiO}_{2}$ anatase phase (JCPDS card no. 21-1272). No feature of $\mathrm{Fe}_{2} \mathrm{O}_{3}$ was detected for $\mathrm{Fe}$-doped sample and all peaks were similar for both doped and undoped samples. It indicated that the $\mathrm{TiO}_{2}$ crystalline structure did not noticeably influenced by low-doping Fe. Raman spectra was used to further investigate the structural changes of $\mathrm{TiO}_{2}$ after doping. All peaks from Raman spectra can be assigned to $E_{\mathrm{g}}\left(147 \mathrm{~cm}^{-1}, 199 \mathrm{~cm}^{-1}\right.$ and $\left.639 \mathrm{~cm}^{-1}\right), B_{1 \mathrm{~g}}\left(398 \mathrm{~cm}^{-1}\right)$ and $A_{1 \mathrm{~g}}+B_{2 \mathrm{~g}}\left(517 \mathrm{~cm}^{-1}\right)$ mode of anatase $\mathrm{TiO}_{2}$, which almost have not change in comparison

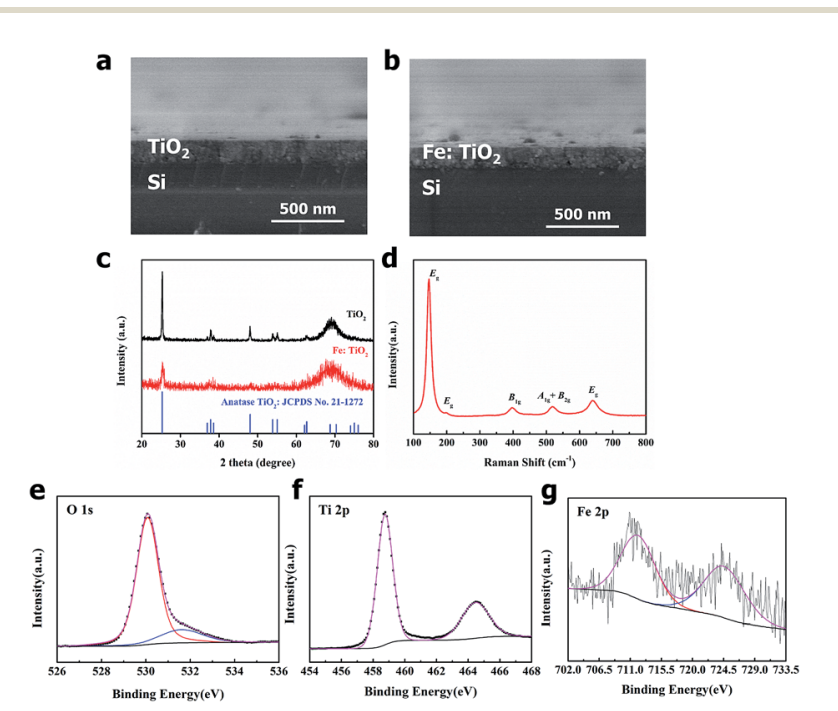

Fig. 1 Characterizations of the $\mathrm{Fe}: \mathrm{TiO}_{2} / \mathrm{Si}$ heterostructure. Crosssectional SEM image of the (a) $\mathrm{TiO}_{2} / \mathrm{Si}$ and (b) $\mathrm{Fe}: \mathrm{TiO}_{2} / \mathrm{Si}$ heterostructure. (c) XRD patterns of pure $\mathrm{TiO}_{2}$ film and $\mathrm{Fe}$-doped $\mathrm{TiO}_{2}$ film. (d) Typical Raman spectrum of the $\mathrm{Fe}: \mathrm{TiO}_{2}$ films. (e, f and g) The corelevel spectra of (e) $\mathrm{O}$ 1s, (f) $\mathrm{Ti} 2 \mathrm{f}$ and (g) Fe 2p in the $\mathrm{Fe}: \mathrm{TiO}_{2}$ films. 
with that of undoped $\mathrm{TiO}_{2}$ due to the low-dose implant for $\mathrm{TiO}_{2}$ (Fig. 1b). XPS analysis was used to investigate the change of surface chemical bonds of the $\mathrm{TiO}_{2}$ nanoparticles induced by iron as shown in Fig. 1e-g. Fig. 1e shows the $\mathrm{O}$ 1s core level spectra of $\mathrm{Fe}: \mathrm{TiO}_{2}$. The peaks at 531.67 and $530.07 \mathrm{eV}$ can be attributed to $\mathrm{Si}-\mathrm{O}$ and $\mathrm{Ti}-\mathrm{O}$ bonds. Ti $2 \mathrm{p}_{1 / 2}$ and $\mathrm{Ti} 2 \mathrm{p}_{3 / 2}$ spinorbital splitting photoelectrons for $\mathrm{Fe}: \mathrm{TiO}_{2}$ sample are located at binding energies of 464.47 and $458.77 \mathrm{eV}$ (Fig. 1f), respectively, which are in agreement with the values of $\mathrm{Ti}^{4+}$ in $\mathrm{TiO}_{2}$. For the low doping level, the signals of Fe are weak (Fig. 1g). The binding energy at $711.27 \mathrm{eV}$ and $724.47 \mathrm{eV}$ should be assigned to $2 \mathrm{p}_{3 / 2}$ and $2 \mathrm{p}_{1 / 2}$ of $\mathrm{Fe}^{3+}$, respectively. These data exhibited a positive shift compared to those in $\mathrm{Fe}_{2} \mathrm{O}_{3}\left(2 \mathrm{p}_{3 / 2}\right.$ and $2 \mathrm{p}_{1 / 2}$ of $\mathrm{Fe}^{3+}$ at $710.7 \mathrm{eV}$ and $724.3 \mathrm{eV}$, respectively), ${ }^{26}$ probably indicative of more positively charged surface $\mathrm{Fe}^{3+}$. The slight enhancement of $\mathrm{Fe} 2 \mathrm{p}$ level binding energy can be attributed to the diffusion of $\mathrm{Fe}^{3+}$ into $\mathrm{TiO}_{2}$ lattice and the formation of $\mathrm{Fe}-\mathrm{O}-\mathrm{Ti}$ bond in the samples. ${ }^{27-30}$

\section{Photoresponse of $\mathrm{Fe}: \mathrm{TiO}_{2} / \mathrm{n}$-Si heterojunction photodetector}

We measured the light intensity dependence of the $\mathrm{Fe}: \mathrm{TiO}_{2} / \mathrm{n}-\mathrm{Si}$ heterojunction PD. Fig. 2a shows the current-voltage $(I-V)$ curves of the Fe: $\mathrm{TiO}_{2} / \mathrm{n}$-Si heterojunction device under $365 \mathrm{~nm}$ light with increasing incident light powers from 0.2 to $1.4 \mathrm{~mW}$ $\mathrm{cm}^{-2}$. The $I-V$ curves of the photodetector exhibited a good rectifying behavior. When the light illuminates on the device, the negative biased current increased with increasing the incident light power. With the reverse voltage increasing, the $I_{\mathrm{ph}}$ (photocurrent) rose sharply and subsequently reached saturation rapidly. The increasing electric field can separate electronhole pairs sufficiently and promptly, giving rise to the increase of the photocurrent. But when the bias is sufficiently large,
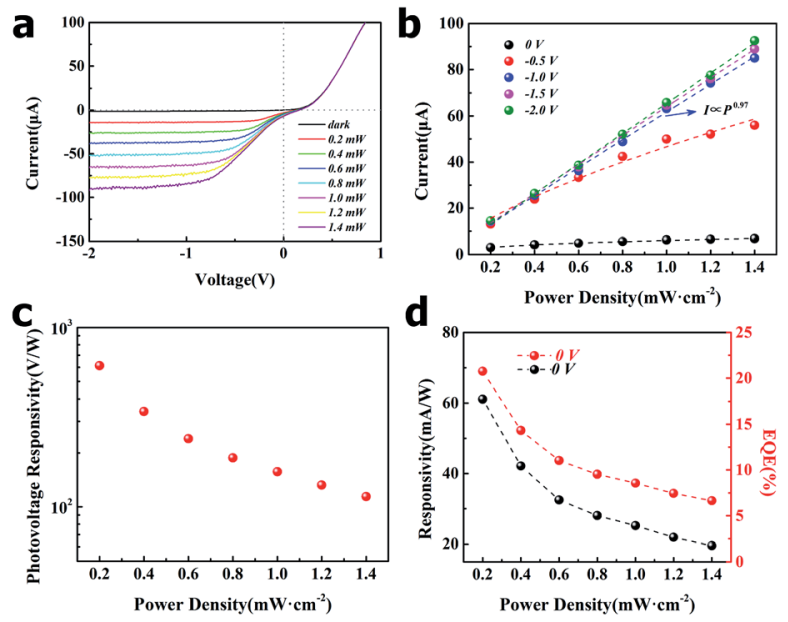

Fig. 2 Photoresponse of $\mathrm{Fe}: \mathrm{TiO}_{2} / \mathrm{Si}$ heterojunction with the device area $=0.25 \mathrm{~cm}^{2}$. (a) $I-V$ characteristics of the heterojunction photodetector under various incident light power. (b) Zero-biased photocurrent under different incident intensity. (c) The photovoltage responsivity as a function of incident light power. (d) Responsivity and EQE under different incident light power at zero bias. With the decrease of light intensity, the EQE increased to $20.8 \%$ at $0.2 \mathrm{~mW}$ $\mathrm{cm}^{-2}$. owing to the available number of charge carriers excited by the fixed illumination power, the photocurrent saturates. ${ }^{28}$ Another interesting finding is that the forward current keeps almost constant regardless of the power density. While in the forward bias, the barrier height and width enlarged, and electrons and holes could not tunnel from it, leading to no variation of forward current. ${ }^{27}$ Fig. $2 \mathrm{~b}$ presents the dependence of photocurrent on the power density at different reverse biases. For lower reverse bias, the photocurrent increased nonlinearly with increasing the power density, while for higher reverse bias, the photocurrent was linearly related to the power density (see Fig. 2b). In general, the dependence of photocurrent on light intensity satisfies the relationship $I_{\mathrm{ph}} \propto P^{\theta}$, where $P$ is the light intensity and $\theta$ is an empirical value related to the recombination processes of the photoexcited carriers. ${ }^{33}$ By fitting the curves in Fig. 2b, we obtained $\theta=0.97$ at reverse bias of $-1 \mathrm{~V}$, indicating that low trap states in $\mathrm{Fe}^{\mathrm{TiO}} \mathrm{Ti}_{2} / \mathrm{n}$-Si heterojunction photodetectors. ${ }^{\mathbf{1 4 , 3 3 , 3 4}}$ Fig. $2 \mathrm{c}$ shows the photovoltage responsivity as a function of the incident light power. The absolute device responsivity $R_{\mathrm{V}}\left(=V_{\mathrm{OC}} / P, V_{\mathrm{OC}}\right.$ is the open-circuit voltage) exceeded $10^{2} \mathrm{VW}^{-1}$ at incident light powers from 0.2 to $1.4 \mathrm{~mW}$ $\mathrm{cm}^{-2}$. It can be as another important parameter for weak signal detection.

Responsivity $(R)$ and external quantum efficiency (EQE) are important quality factors for photodetectors, which can be given by the following formulas:

$$
\begin{aligned}
& R=\frac{I_{\mathrm{ph}}-I_{\mathrm{d}}}{P S} \\
& \mathrm{EQE}=\frac{h c}{e \lambda} R
\end{aligned}
$$

where the $I_{\mathrm{ph}}, I_{\mathrm{d}}, P, S, h, c, e, \lambda$ are the photocurrent, the dark current, the light power density, the effective area under irradiation, Planck's constant, the velocity of light, the electronic charge, and the wavelength of illuminated light, respectively. In Fig. $2 \mathrm{~d}, R$ value was as high as $60 \mathrm{~mA} \mathrm{~W}^{-1}$ at zero bias under a relatively low light intensity of $0.2 \mathrm{~mW} \mathrm{~cm}^{-2}$. Notably, $R$ value tended to decrease at high light intensity, which may be attributed to the increased carrier recombination with increasing light intensity. ${ }^{31}$ Furthermore, EQE of the Fe:TiO ${ }_{2} / \mathrm{Si}$ heterostructure detector was determined to be $20 \%$ at lower illumination intensity of $0.2 \mathrm{~mW} \mathrm{~cm} \mathrm{~cm}^{-2}$, which indicated photocarriers can be effectively generated in the heterostructure.

To further investigate the wavelength-dependent characteristics of $\mathrm{Fe}: \mathrm{TiO}_{2} / \mathrm{n}$-Si heterojunction, $I-V$ curves were recorded when the wavelength of the incident radiation was switched from 350 to $600 \mathrm{~nm}$ at a constant intensity of $0.5 \mathrm{~mW} \mathrm{~cm}^{-2}$ (Fig. 3). The photocurrent of $\mathrm{Fe} \mathrm{TiO}_{2} / \mathrm{n}-\mathrm{Si}$ heterojunction was found to depend on the wavelength of the incident radiation. As shown in Fig. 3a, the photocurrent of the device increased quickly from $-5.77 \mu \mathrm{A}$ at $350 \mathrm{~nm}$ to $-7.67 \mu \mathrm{A}$ at the wavelength of $600 \mathrm{~nm}$. The wavelength dependence of both photocurrent responsivity and EQE of the device are presented in Fig. $3 \mathrm{~b}$ and c, respectively. Fig. 3d shows the photocurrent responsivity and EQE with different incident light wavelengths at zero bias. Notably, the EQE exceeded $10 \%$ when the wavelength of the 

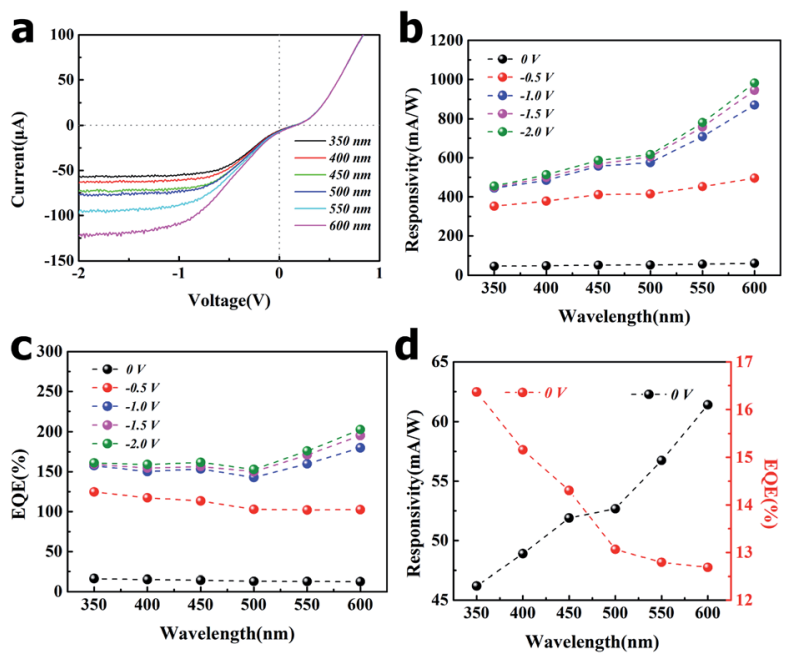

Fig. 3 Photoresponse of $\mathrm{Fe}: \mathrm{TiO}_{2} / \mathrm{Si}$ heterojunction with the device area $=0.25 \mathrm{~cm}^{2}$. When the wavelength of the incident radiation was switched from 350 to $600 \mathrm{~nm}$ at a constant intensity of $0.5 \mathrm{~mW} \mathrm{~cm}$. (a) $I-V$ characteristics of the heterojunction photodetector with various incident light wavelengths. The wavelength dependence of both (b) photocurrent responsivity and (c) EQE of the heterojunction under different biases. (d) Responsivity and EQE with different incident light wavelengths at zero bias. The EQE exceeded $10 \%$ when the wavelength of the incident radiation was switched from 350 to $600 \mathrm{~nm}$

incident radiation was switched from 350 to $600 \mathrm{~nm}$ at a constant intensity of $0.5 \mathrm{~mW} \mathrm{~cm}{ }^{-2}$. Furthermore, EQE of the heterojunction rose up beyond $100 \%$ with a broad wavelength range at a small reverse bias of $-0.5 \mathrm{~V}$ (Fig. $3 \mathrm{c}$ ). Fig. $\mathrm{S} 1 \uparrow$ shows photoresponse characteristics of sample B, C and D. The results indicate that the as-fabricated $\mathrm{Fe}: \mathrm{TiO}_{2} / \mathrm{Si}$ PDs have excellent reproducibility, suggesting a promising direction for manufacturing advanced self-powered PDs.

Fig. 4a is one cycle of the time-resolved photoresponse of the device at zero bias upon $365 \mathrm{~nm}$ light illumination at light intensity of $1.0 \mathrm{~mW} \mathrm{~cm} \mathrm{~m}^{-2}$. Photoresponse time is defined as the time of switching duration from $10 \%$ to $90 \%$ of the pulse peak. From rising and falling edges, we can get rising time $t_{\mathrm{r}}=10 \mathrm{~ms}$, falling time $t_{\mathrm{f}}=15 \mathrm{~ms}$, respectively (detectable limit of our instrument). In Fig. 4b, the two on/off operational measurements interval one month maintained almost the same light response behaviors. Furthermore, our PDs showed strong response at zero bias voltage toward UV-visible light $\left(0.5 \mathrm{~mW} \mathrm{~cm}^{-2}, \lambda=365,400\right.$, 450, 500, 550 and $600 \mathrm{~nm}$ ) as shown in Fig. 4c, suggesting a broadband detection spectrum. We collected photocurrent under different wavelengths with the same light power, and found that the linear correlation between photocurrent and the number of incident photons (see Fig. S2, ESI $\dagger$ ). The biasdependent switching characteristics of the photodetector were investigated by applying different bias voltages of $0,-0.5,-1.0$, -1.5 , and $-2.0 \mathrm{~V}$ to the device is shown in Fig. $4 \mathrm{~d}$. As the bias voltage increases, the photocurrent increases significantly and eventually reaches a substantially constant. This result provides the possibility of adjusting the optical response of the device by applying an appropriate range of bias voltages.
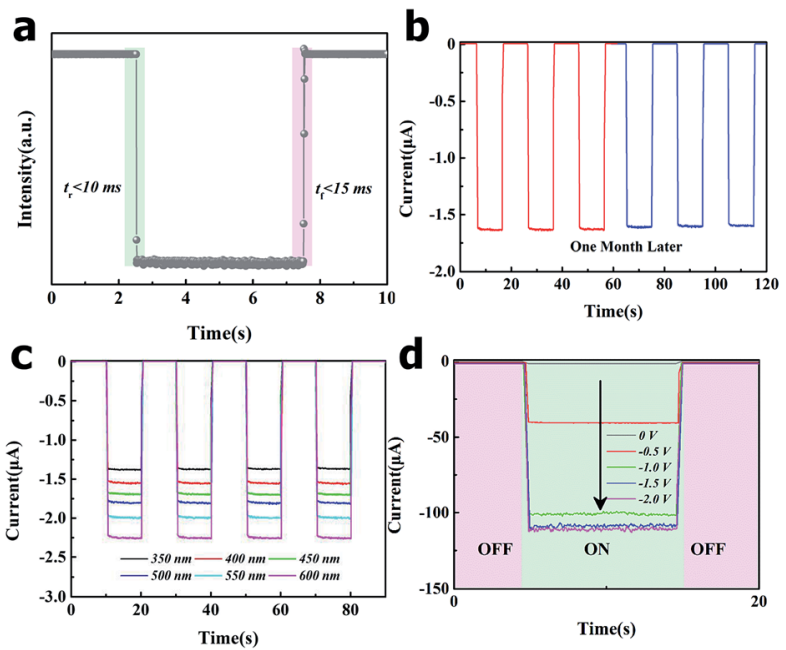

Fig. 4 Time-dependent photocurrent response of the $\mathrm{Fe}: \mathrm{TiO}_{2} / \mathrm{Si}$ device. (a) One cycle of photoswitching photocurrent at zero bias with a light of $365 \mathrm{~nm}$. When the light is on, photocurrent increases sharply, and the rising photoresponse time is less than $10 \mathrm{~ms}$. When the light is off, the photocurrent decreases to zero promptly, and the falling photoresponse time is less than $15 \mathrm{~ms}$. (b) Stability measurement of device. The two on/off operational measurements interval one month maintained almost the same light response behaviors. (c) The photoresponse under various excitation wavelengths with the same light intensity of $0.5 \mathrm{~mW} \mathrm{~cm}^{-2}$. (d) Photocurrent switching behaviors obtained under different reverse bias voltages.

Excellent photoresponse of the $\mathrm{Fe} \mathrm{TiO}_{2} / \mathrm{Si}$ heterojunction device can be explained by the processes of photo-excitation and carrier transport in the junction illustrated in energy band diagram (see Fig. 5). The Fe doped $\mathrm{TiO}_{2}$ layer could absorb UV light and part of short-wavelength visible light (see Fig. 5b and c). The photogenerated electron-hole pairs are only created inside $\mathrm{TiO}_{2}$ side under UV light and part of short-wavelength visible light, while the electron-hole pairs are only created inside Si side under visible light. $\mathrm{TiO}_{2}$ and $\mathrm{Si}$ form a space charge region as shown in Fig. 5b where part of the photogenerated electrons diffuse from $\mathrm{TiO}_{2}$ towards the junction and are swept into $\mathrm{Si}$, while the photo-generated holes are confined in the Si side because of the large valence band offset. Since the presence of an internal electric field (at space charge region) facilitates the separation of electron-hole pairs under UV-visible light irradiation, which significantly reduces the electron-hole recombination ratio, resulting in much higher
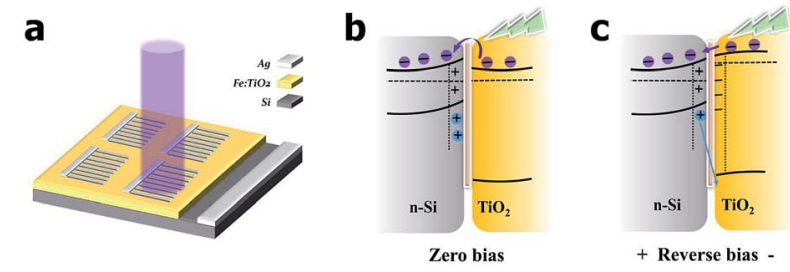

Fig. 5 (a) Illustration of the schematic device. Schematic representation of the band energies and charge transfer of the $\mathrm{Si}(111) / \mathrm{TiO}_{2}$ film under illumination with (b) zero bias and (c) reverse bias, respectively. 
photocurrent. In the case of the reverse bias (positive bias is applied on Si sides shown in Fig. 5c), with the same direction of the internal electrical field, could promote the separation of the electron-hole pairs. Meanwhile, the width of the depletion layer narrows (the height of the barrier becomes low), and the generated electrons in the space charge region of $\mathrm{TiO}_{2}$ could transport through the depletion layer driven by the applied bias. $^{35}$

High depletion region of heterostructure holds a powerful built-in electric field that rapidly separates photon-generating carriers, leading high quantum efficiency and fast response speed during thermal equilibrium. This make our PDs show self-powered properties with very fast temporal response, as well as excellent EQE and responsivity in UV-visible region. In addition, the vertical conductive distance between $\mathrm{TiO}_{2}$ film and the electrodes prevents unnecessary recombination, thereby further improving the response speed..$^{31,32,36,37}$ In Fig. S3, $\uparrow$ compared to $\mathrm{TiO}_{2}$ thin film PD in photoconductive mode, heterostructure $\mathrm{PD}$ has higher responsivity and faster response speed. Fig. $\mathrm{S} 5 \dagger$ shows the PL spectra of pure $\mathrm{TiO}_{2}$ film and Fe-doped $\mathrm{TiO}_{2}$ film. The intensity increase of the PL from the Fe-doped $\mathrm{TiO}_{2}$, compared to pure $\mathrm{TiO}_{2}$, which indicated higher carrier concentration. Furthermore, a strong accelerating electric field is easily formed on thin film at the applied reverse bias, which could facilitate carrier separation and produce external gain. ${ }^{38}$ Moreover, the increased donor density of Fe-doped sample is expected to shift the Fermi level of $\mathrm{TiO}_{2}$ toward the conduction band. The upward shift of the Fermi level facilitates the charge separation at the interface by increasing the degree of band bending at the $\mathrm{TiO}_{2}$ surface. The enhanced charge separation and transportation are the major reasons for the observed better performance enhancement.

To verify the presence of built-in electric fields, the capacitance-voltage $(C-V)$ measurements were conducted. As shown in Fig. 6, the $C-V$ curves were performed at $10 \mathrm{kHz}$ in dark condition (black curve line). Further analysis about the interface could be given by Mott-Schottky plot (red curve line). Based on the equation: ${ }^{39}$

$$
\frac{1}{C^{2}}=\left(\frac{2}{q \varepsilon_{\mathrm{s}} \varepsilon_{0} N_{\mathrm{d}} A^{2}}\right)\left(V+V_{\mathrm{bi}}\right)
$$

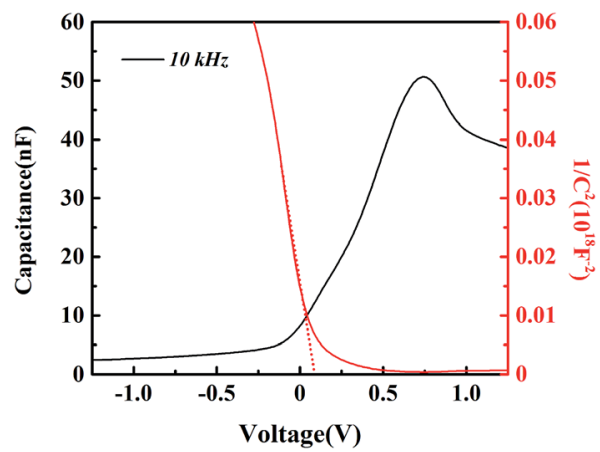

Fig. 6 Capacitance-voltage measurement and Mott-Schottky plots of the $\mathrm{Fe}: \mathrm{TiO}_{2} / \mathrm{n}$-Si heterojunction at $10 \mathrm{kHz}$ frequency. where $q$ is the elementary charge, $\varepsilon_{\mathrm{s}}$ is the dielectric constant of $\mathrm{Si}, \varepsilon_{0}$ is the permittivity of a vacuum, $N_{\mathrm{d}}$ is carrier density of $\mathrm{n}-\mathrm{Si}$, $V$ is the applied potential, and $V_{\mathrm{bi}}$ is the built-in potential. The $C-V$ characteristic of the photodetector shows a typical $\mathrm{p}-\mathrm{n}$ junction behavior. The capacitance decreased quickly as the reverse voltage increasing, due to the increase in the depletion layer width of the heterojunction. The increased depletion width would beneficial to the improvement of the photosensitivity and enhance the response speed. According to the $1 / C^{2}$ versus $V$ plot shown in Fig. 6 (red curve line), the value of $V_{\mathrm{bi}}-$ $k T / q$ was determined to be $\approx 0.12 \mathrm{~V}$ by extending the straight line to the voltage axis ( $k T / q$ is equal to $0.026 \mathrm{~V}$ at the temperature of $300 \mathrm{~K})$. So the potential voltage caused by the internal electrical field $\left(V_{\mathrm{bi}}\right)$ was deduced as $0.15 \mathrm{~V}$.

\section{Conclusions}

In summary, self-powered UV-visible PDs employing heterojunction between the $\mathrm{Fe}: \mathrm{TiO}_{2}$ and $\mathrm{Si}$ was fabricated via a facile solution process. The existence of built-in electric field between Fe: $\mathrm{TiO}_{2}$ and Si help facilitate the separation of photo-generated electron-hole pairs and regulate the electron transport. A fast response speed of 10/15 ms were achieved. Under zero bias, the device exhibited high responsivity of $46 \mathrm{~mA} \mathrm{~W}^{-1}(350 \mathrm{~nm})$ and $60 \mathrm{~mA} \mathrm{~W}^{-1}(600 \mathrm{~nm})$ with a $0.5 \mathrm{~mW} \mathrm{~cm}^{-2}$ light irradiation. At a small reverse bias of $-0.5 \mathrm{~V}$, the EQE of the PD rose up beyond $100 \%$ with a broad wavelength range. The exploring of $\mathrm{Fe}: \mathrm{TiO}_{2} /$ n-Si heterojunction PD demonstrates an ultrasensitive, fast, and broad-band (UV-visible) photodetection with no or low external energy supply. We expect a productive future for the selfpowered PDs integrated on flexible platforms, even multifunctional and smart systems.

\section{Conflicts of interest}

There are no conflicts to declare.

\section{Acknowledgements}

This work was supported by the National Natural Science Foundation of China under Grant No. 11174049 and 61376017, and the NSFC-NRF Scientific Cooperation Program, Brain Pool Program of Korea under grant: 171S-1-3-1829. J. W. would like to acknowledge Shanghai Talent Development Funding for financial support.

\section{References}

1 Z. L. Wang, Adv. Mater., 2012, 24, 280-285.

2 L. Peng, L. Hu and X. Fang, Adv. Funct. Mater., 2014, 24, 2591-2610.

3 L. Zheng, K. Hu, F. Teng and X. Fang, Small, 2017, 13, 1602448.

4 Y. Q. Bie, Z. M. Liao, H. Z. Zhang, G. R. Li, Y. Ye, Y. B. Zhou, J. Xu, Z. X. Qin, L. Dai and D. P. Yu, Adv. Mater., 2011, 23, 649-653. 
5 J. Y. Zhou, L. L. Chen, Y. Q. Wang, Y. M. He, X. J. Pan and E. Q. Xie, Nanoscale, 2016, 8, 50-73.

6 X. Li, C. Gao, H. Duan, B. Lu, Y. Wang, L. Chen, Z. Zhang, X. Pan and E. Xie, Small, 2013, 9, 2005-2011.

7 A. A. Hussain, B. Sharma, T. Barman and A. R. Pal, ACS Appl. Mater. Interfaces, 2016, 8, 4258-4265.

8 X. Wang, P. Wang, J. Wang, W. Hu, X. Zhou, N. Guo, H. Huang, S. Sun, H. Shen, T. Lin, M. Tang, L. Liao, A. Jiang, J. Sun, X. Meng, X. Chen, W. Lu and J. Chu, Adv. Mater., 2015, 27, 6575-6581.

9 B. Nie, J. G. Hu, L. B. Luo, C. Xie, L. H. Zeng, P. Lv, F. Z. Li, J. S. Jie, M. Feng, C. Y. Wu, Y. Q. Yu and S. H. Yu, Small, 2013, 9, 2872-2879.

10 D. Zheng, H. Fang, P. Wang, W. Luo, F. Gong, J. C. Ho, X. Chen, W. Lu, L. Liao, J. Wang and W. Hu, Adv. Funct. Mater., 2016, 26, 7690-7696.

11 Z. Zhang, Q. Liao, Y. Yu, X. Wang and Y. Zhang, Nano Energy, 2014, 9, 237-244.

12 I. S. Jeong, J. H. Kim and S. Im, Appl. Phys. Lett., 2003, 83, 2946-2948.

13 Y. Li, C. Y. Xu, J. Y. Wang and L. Zhen, Sci. Rep., 2014, 4, 7186.

14 H. Zhang, X. Zhang, C. Liu, S. T. Lee and J. Jie, ACS Nano, 2016, 10, 5113-5122.

15 A. Midya, A. Ghorai, S. Mukherjee, R. Maiti and S. K. Ray, J. Mater. Chem. A, 2016, 4, 4534-4543.

16 Y. Wang, K. Ding, B. Sun, S.-T. Lee and J. Jie, Nano Res., 2016, 9, 72-93.

17 T. Ji, Q. Liu, R. Zou, Y. Sun, K. Xu, L. Sang, M. Liao, Y. Koide, L. Yu and J. Hu, Adv. Funct. Mater., 2016, 26, 1400-1410.

18 J. Guo, Z. Gan, Z. Lu, J. Liu, J. Xi, Y. Wan, L. Le, H. Liu, J. Shi and R. Xiong, J. Appl. Phys., 2013, 114, 104903.

19 C.-C. Wang, K.-W. Wang and T.-P. Perng, Appl. Phys. Lett., 2010, 96, 143102.

20 R. Asahi, T. Morikawa, T. Ohwaki, K. Aoki and Y. Taga, Science, 2001, 293, 269-271.

21 W. Li, Y. Wang, H. Lin, S. Ismat Shah, C. P. Huang, D. J. Doren, S. A. Rykov, J. G. Chen and M. A. Barteau, Appl. Phys. Lett., 2003, 83, 4143-4145.
22 I. S. Cho, C. H. Lee, Y. Feng, M. Logar, P. M. Rao, L. Cai, D. R. Kim, R. Sinclair and X. Zheng, Nat. Commun., 2013, 4, 1723. 23 M. Anpo and M. Takeuchi, J. Catal., 2003, 216, 505-516.

24 L. Zheng, P. Yu, K. Hu, F. Teng, H. Chen and X. Fang, ACS Appl. Mater. Interfaces, 2016, 8, 33924-33932.

25 H. Zhou, Z. Song, P. Tao, H. Lei, P. Gui, J. Mei, H. Wang and G. Fang, RSC Adv., 2016, 6, 6205-6208.

26 C. D. Wagner, W. M. Riggs, L. E. Davis and J. F. Moulder, Handbook of X-Ray Photoelectron Spectroscopy, ed. G. E. Muilenberg, Perkin Elmer Corporation, Eden Prairie, 1979.

27 J. Zhu, F. Chen, J. Zhang, H. Chen and M. Anpo, J. Photochem. Photobiol., A, 2006, 180, 196-204.

28 M. Zhou, J. Yu and B. Cheng, J. Hazard. Mater., 2006, 137, 1838-1847.

29 M. Zhou, J. Yu, B. Cheng and H. Yu, Mater. Chem. Phys., 2005, 93, 159-163.

30 J. Yu, H. Yu, C. H. Ao, S. C. Lee, J. C. Yu and W. Ho, Thin Solid Films, 2006, 496, 273-280.

31 X. Yuan, L. Tang, S. Liu, P. Wang, Z. Chen, C. Zhang, Y. Liu, W. Wang, Y. Zou, C. Liu, N. Guo, J. Zou, P. Zhou, W. Hu and F. Xiu, Nano Lett., 2015, 15, 3571-3577.

32 Y. Li, C. Y. Xu, J. Y. Wang and L. Zhen, Sci. Rep., 2014, 4, 7186.

33 H. Kind, H. Q. Yan, B. Messer, M. Law and P. D. Yang, Adv. Mater., 2002, 14, 158.

34 C. Xie, X. Zhang, Y. Wu, X. Zhang, X. Zhang, Y. Wang, W. Zhang, P. Gao, Y. Han and J. Jie, J. Mater. Chem. A, 2013, 1, 8567.

35 J. Qi, X. Hu, Z. Wang, X. Li, W. Liu and Y. Zhang, Nanoscale, 2014, 6, 6025-6029.

36 S. M. Sze, Semiconductor Devices: Physics and Technology, John Wiley \& Sons, 2008.

37 P. Wang, S. Liu, W. Luo, H. Fang, F. Gong, N. Guo, Z. G. Chen, J. Zou, Y. Huang, X. Zhou, J. Wang, X. Chen, W. Lu, F. Xiu and W. Hu, Adv. Mater., 2017, 29, 1604439.

38 M. Liao, X. Wang, T. Teraji, S. Koizumi and Y. Koide, Phys. Rev. B: Condens. Matter Mater. Phys., 2010, 81, 033304.

39 J. Bisquert, Nanostructured Energy Devices: Equilibrium Concepts and Kinetics, CRC Press, Boca Raton, 2014. 